\title{
Single-Step Grafting of Aminooxy-Peptides to Hyaluronan: A Simple Approach to Multifunctional Therapeutics for Experimental Autoimmune Encephalomyelitis
}

\author{
Joshua. Sestak ${ }^{1}$, Meagan Mullins ${ }^{1}$, Laura Northrup ${ }^{1}$, Shara Thati ${ }^{1}$, Teruna Siahaan ${ }^{1}$, and \\ Cory Berkland ${ }^{1,2,{ }^{*}}$ \\ ${ }^{1}$ Department of Pharmaceutical Chemistry, University of Kansas, 2030 Becker Dr, Lawrence, KS \\ 66047 \\ 2 Department of Chemical and Petroleum Engineering, University of Kansas, 1530 W 15th, Rm \\ 4132 Learned Hall, Lawrence, KS, 66045
}

\section{Abstract}

The immune response to antigens is directed in part by the presence or absence of costimulatory signals. The ability to coincidently present both antigen and, for example, a peptide that inhibits or activates the costimulatory pathway, would be a valuable tool for tolerization or immunization, respectively. A simple reaction scheme utilizing oxime chemistry was identified as a means to efficiently conjugate different peptide species to hyaluronan. Peptides synthesized with an aminooxy $\mathrm{N}$-terminus reacted directly to hyaluronan under slightly acidic aqueous conditions without the need for a catalyst. The resulting oxime bond was found to rapidly hydrolyze at $\mathrm{pH} 2$ releasing peptide, but was stable at higher $\mathrm{pH}$ values (5.5 and 7). Two different peptide species, a multiple sclerosis antigen (PLP) and an ICAM-1 ligand (LABL) known to block immune cell stimulation, were functionalized with the aminooxy end group. These peptides showed similar reactivity to hyaluronan and were conjugated in an equimolar ratio. The resulting hyaluronan with grafted PLP and LABL significantly inhibited disease in mice with experimental autoimmune encephalomyelitis, a model of multiple sclerosis. Aminooxy-peptides facilitate simple synthesis of multifunctional hyaluronan graft polymers, thus enabling novel approaches to antigen-specific immune modulation.

\section{Keywords}

Oxime; aminooxy; hyaluronan; conjugation; graft polymer

\section{INTRODUCTION}

The emergence of nanotechnology has heighted appreciation for the effect of ligand valency and density, a physical component of molecular signaling. Although carefully synthesized colloids have become important in this endeavor, researchers have utilized graft polymers to deliver multivalent signals for decades.[1-5] Antigens grafted to keyhole limpet hemocyanin

\footnotetext{
(C) 2013 Elsevier B.V. All rights reserved.

*Corresponding Author; berkland@ku.edu.

Publisher's Disclaimer: This is a PDF file of an unedited manuscript that has been accepted for publication. As a service to our customers we are providing this early version of the manuscript. The manuscript will undergo copyediting, typesetting, and review of the resulting proof before it is published in its final citable form. Please note that during the production process errors may be discovered which could affect the content, and all legal disclaimers that apply to the journal pertain.
} 
represented an early vaccination scheme that is still employed.[6-9] Today, peptides are routinely grafted to polymers or to colloids to target drug delivery, mediate endocytosis, promote tissue growth, modify immune response, and myriad other functions.[10-13] Grafted peptide number and density have now been recognized as key determinants of molecular response for many of these systems.[14-17]

Conjugation reactions to orthogonally graft peptides to biological polymers under benign conditions are, therefore, highly desired tools for mediating multivalent molecular interactions. In particular, current synthetic approaches for conjugating peptides to glycosaminoglycans would benefit from simplified reaction schemes.[18] These fragile biological polymers cannot be exposed to many of the conditions required for traditional conjugation methods (e.g. solvent, $\mathrm{pH}$, temperature) due to stability concerns.[12] In addition, current approaches often utilize multiple steps, such as activation procedures to form reactive intermediates or the addition of linker molecules to facilitate stability or to improve reaction efficiency.[11, 19, 20] These encumbrances coupled with low product yields and lengthy purification procedures make many of the current conjugation schemes inconvenient for translational medicine or assays and impractical for scale-up.[11, 21] Further problems emerge when conjugating multiple different peptides since small differences in reactivity may yield unpredictable molar ratios.[22] Such issues hinder the exploration of multivalent or multifunctional polymers or colloids with defined ligand densities and ratios.

Oxime chemistry has emerged as a promising conjugation scheme that traditionally utilizes the highly specific reaction of aminooxy groups to aldehydes or ketones.[23-26] The reaction can be carried out in water and avoids harsh catalysts or reaction conditions.[27] In addition, aminooxy reactivity is significantly higher than primary amines, thus conferring the desired specificity for conjugation schemes using polypeptides.[18, 25, 28] One drawback to this approach has been the need for available aldehyde or ketone groups to provide a reactive site, a characteristic that usually necessitates engineering the reactant. Recent reports, however, have suggested aminooxy compounds reacted directly to unmodified hyaluronan, thus prompting exploration of oxime chemistry for orthogonal peptide grafting to this glycosaminoglycan.[23, 29, 30]

Hyaluronan is a flexible, highly water soluble polymer that has been translated into a variety of medical products, making it an attractive backbone for multivalent peptide grafting. Additionally, researchers have shown that controlling the size of the hyaluronan scaffold facilitates placement into lymph nodes after subcutaneous injection. Specifically, hyaluronan conjugates between $40-80 \mathrm{kDa}$ showed a high degree of accumulation in lymph nodes and minimal systemic exposure [31]. Thus, hyaluronan conjugates in this size range can passively carry drugs (e.g. immune modulators) to lymph nodes as a means to modify immune response. In the first part of this paper, oxime chemistry was confirmed as a unique and simple approach for grafting small molecules or peptides to hyaluronan to create a lymphatic delivery system.

Furthermore, simultaneous delivery of antigen and an immune modulator represents an attractive approach to antigen-specific immunotherapy. LABL is a peptide that inhibits the binding of intracellular cell-adhesion molecule-1 (ICAM-1) [32]. This peptide was also shown to interfere with immune cell adhesion in immortalized and primary cell culture models [33-35]. Coincident delivery of antigen and LABL, therefore, may inhibit the inflammatory immune response and provide 'antigen-specific' therapy for treating autoimmune diseases. Hyaluronan co-grafted with aminooxy-PLP (a multiple sclerosis antigen) and with aminooxy-LABL was administered subcutaneously in the experimental 
autoimmune encephalomyelitis murine model of multiple sclerosis to test the efficacy of this oxime grafting scheme.

\section{MATERIALS AND METHODS}

\section{Peptide Synthesis}

Aminooxy peptides were synthesized using 9-fluorenylmethyloxycarbonyl-protected amino acid chemistry on polyethylene glycol-polystyrene resins. The peptides synthesized were aminooxy-LABL (aminooxy-ITDGEATDSG, $A o$-LABL), a cell-adhesion molecule antagonist, and aminooxy-proteolipid peptide (PLP) (aminooxy-HSLGKWLGHPDKF, AoPLP), a known antigen epitope in multiple sclerosis. Peptides were deprotected, cleaved from resin, and isolated by precipitation in ether. Purification was completed using preparatory high performance liquid chromatography (HPLC) followed by lyophilization. Peptide purity was assessed using analytical HPLC and the identity of the synthesized peptide was confirmed by electrospray ionization mass spectrometry.

\section{Reaction of Aminooxy Molecules to Monomer/Polymer}

The reaction conditions were identical for all reactants used (OCMH, OBZ, OPH, LABL peptide, PLP peptide). Aminooxy monomer was mixed with HA in 1:5 excess in acetate buffered solution ( $\mathrm{pH}$ 5.5). After addition of all reactive species, the $\mathrm{pH}$ was measured and adjusted to $5.5 \pm 0.1$. For reactions, $1.3 \mu \mathrm{Mol} \mathrm{HA}$ was dissolved into $20 \mathrm{mM}$ acetate buffered solution ( $\mathrm{pH} 5.5 \pm 0.1$ ). Once dissolved, $1.3 \mu \mathrm{Mol}$ aminooxy-peptide was added to the solution. When more than one peptide species was added, $0.65 \mu \mathrm{Mol}$ of each peptide was weighed out separately, then both were added simultaneously. After addition of the aminooxy species, the reaction solution $\mathrm{pH}$ was adjusted to $\mathrm{pH} 5.5 \pm 0.1$. The solution was mixed for $16 \mathrm{hr}$ at room temperature. After 16 hours, the samples were dialyzed against ddH2O to remove unreacted peptide. Dialysis water was changed every 6 hours for 24 hours. After dialysis, the dialysate was frozen at $-70{ }^{\circ} \mathrm{C}$ and lyophilized. For kinetic experiments, samples were taken from the reaction vessel at predetermined time points and analyzed immediately.

\section{Fourier Transform Infrared Spectroscopy}

Changes in bonding environments during reaction were monitored using a Bruker Tensor 27 FTIR spectrometer equipped with a ZnSe attenuated total reflectance (ATR) plate (Pike Technologies). Fourier transform infrared (FTIR) spectra were collected at room temperature $\left(25^{\circ} \mathrm{C}\right)$. Data were collected over 256 composite scans with a resolution of 4 $\mathrm{cm}-1$. The samples were analyzed in $20 \mathrm{mM}$ acetate buffer at a con- centration of $3 \mathrm{mg} / \mathrm{mL}$. Spectra from buffer alone were subtracted from reactant and product spectra using the OPUS spectroscopy software and data were further analyzed using GRAMS/AI (Galactic, Inc.).

\section{Nuclear Magnetic Resonance Spectroscopy}

For structural analysis of the various reactants and conjugates, samples were dissolved in D2O to a concentration of $10 \mathrm{mg} / \mathrm{mL}$. H1 and C13 spectra were acquired on a Bruker 400 $\mathrm{MHz}$ spectrometer at $25^{\circ} \mathrm{C}$.

\section{Gel Permeation Chromatography}

The change in molecular weight of HA graft polymer conjugates was determined using a Viscotek GPC max VE 2001 GPC solvent/sample module, VE3580 refractive index detector, and 270 Dual Detector with right angle light scattering. Samples were separated by utilizing a tandem column setup of an Agilent PL aquagel-OH 60 and Agilent PL aquagel- 
$\mathrm{OH} 40$ column in seris. Columns were heated to $45^{\circ} \mathrm{C}$ using an Eldex $\mathrm{CH}-150$ heating box. All pullulan standards and graft polymer conjugates were separated in a $0.1 \mathrm{M}$ Ammonium Acetate, $\mathrm{pH} 5.0$, with $0.25 \mathrm{M} \mathrm{NaCl}$ Mobile phase for $30 \mathrm{~min}$.

\section{High Performance Liquid Chromatography}

Peptide was quantified by gradient reversed- phase HPLC (SHIMADZU) using a Vydac HPLC protein and peptide C18 column. The HPLC consisted of a SCL-20A SHIMADZU system controller, LC-10AT VP SHIMADZU liquid chromatograph, SIL-10A XL SHIMADZU auto-injector set at $75 \mu \mathrm{L}$ injection volume, DGU-14A SHIMADZU degasser, sample cooler, and SPD-10A SHIMADZU UV-vis detector $(220 \mathrm{~nm})$. The HPLC-UV system was controlled by a personal computer equipped with SHIMADZU class VP Software. Gradient elution was carried out at constant flow of $1 \mathrm{~mL} / \mathrm{min}$, from $100 \%$ A to $35 \% \mathrm{~A}$ (corresponding to $0 \% \mathrm{~B}$ to $65 \% \mathrm{~B}$ ) for $50 \mathrm{~min}$, followed by an isocratic elution at $75 \%$ B for 3 min. Mobile phase compositions were (A) acetonitrile-water (5:95) with $0.1 \%$ TFA and(B) acetonitrile-water 90:10, v/v) with $0.1 \%$ TFA. At the end of each analysis, the cartridge was equilibrated at initial conditions at $1 \mathrm{~mL} / \mathrm{min}$ flow rate for $5 \mathrm{~min}$ with A.

\section{Induction of EAE and Therapeutic Study}

SJL/J (H-2s) female mice, $4-6$ weeks old, were purchased from Charles River Laboratory and housed under specified, pathogen-free conditions at The University of Kansas. All protocols involving live mice were approved by the Institutional Animal Care and Use Committee. Mice were immunized subcutaneously with $200 \mathrm{mg}$ of PLP139-151 in a $0.2 \mathrm{~mL}$ emulsion composed of equal volumes of phosphate-buffered saline (PBS) and complete Freund's adjuvant (CFA) containing killed Mycobacterium tuberculosis strain H37RA (final concentration of $4 \mathrm{mg} / \mathrm{mL}$; Difco). The PLP139-151/CFA was administered to regions above the shoulders and the flanks (total of four sites; $50 \mu \mathrm{L}$ at each injection site). In addition, $200 \mathrm{ng} / 100 \mu \mathrm{L}$ of pertussis toxin (List Biological Laboratories Inc.) was injected intraperitoneally on the day of immunization (day 0 ) and 2 days post-immunization. The mice received s.c. injections of each sample, equivalent to $100 \mathrm{nMol}$ PLP $/ 100 \mu \mathrm{L}$, on days 4,7 , and 10. For all samples and controls, $100 \mu \mathrm{L}$ of each was injected. Disease progression was evaluated blindly by the same observer using clinical scoring as follows: 0 , no clinical signs of the disease; 1 , tail weakness or limp tail; 2, paraparesis (weakness or incomplete paralysis of one or two hind limbs); 3, paraplegia (complete paralysis of two hind limbs); 4, paraplegia with forelimb weakness or paralysis; and 5, moribund (mice were euthanized if they were found to be moribund). Body weight was also measured daily.

\section{Statistical Analysis}

Statistical differences were determined by comparing treated groups to the negative control (PBS) for clinical disease score and body weight. A one-way analysis of variance (ANOVA) followed by Fisher's least significant difference was applied to these data. All analyses were performed using GraphPad Software (GraphPad Software Inc.).

\section{RESULTS}

Intial studies focused on confirming reactivity of aminooxy-containing molecules and the glycosaminoglycan hyaluronic acid (HA). The small molecules used were $O$-carboxymethyl hydroxylamine (OCMH), $O$-benzyl hydroxylamine (OBZ), and $O$-phenyl hydroxylamine $(\mathrm{OPH})$. The structures of these molecules and the HA monomer unit are shown in Table 1.

Fourier Transform Infrared Spectroscopy (FT-IR) was used as a preliminary technique to investigate reactivity between these aminooxy compounds and HA. Data showed distinct changes in the FT-IR bonding environments when reacting either OCMH or OBZ (Figure 
1). In both product spectra, a new bonding environment appeared at $1750 \mathrm{~cm}-1$ as well as a distortion of the amide I peak at $1600 \mathrm{~cm}-1$. The peak at $1750 \mathrm{~cm} \mathrm{-1}$ is representative of formation of an oxime bond in the product. Additionally, the peak at $1500 \mathrm{~cm}-1$ disappeared and the peak environment around $1400 \mathrm{~cm}-1$ was altered in both products, which may suggest a change in the carboxylic acid environment of the HA.

Analysis of products by $1 \mathrm{H}$ NMR showed the appearance of new peaks in the product spectra. The proton spectra for the OCMH conjugate (Figure 2B) and OBZ conjugate (Figure 2C) showed three new peaks at $5.3 \mathrm{ppm}, \sim 6.9$ and $7.5 \mathrm{ppm}$, and $8 \mathrm{ppm}$ when compared to the HA polymer alone. In the OBZ spectra, there was an additional peak environment at $7.3 \mathrm{ppm}$, however, this was due to the presence of the aromatic ring and not associated with oxime bond formation. The environment at $5.3 \mathrm{ppm}$ is indicative of the hydrogens alpha to the aminooxy $\mathrm{O}-\mathrm{NH}_{2}$. The doublet environments at $\sim 6.9$ and $7.5 \mathrm{ppm}$ are suggestive of the cis- and trans-conformation of the amide methyl group after addition. Lastly, the environment at 8 ppm suggests addition at the carboxylic acid. Peak shifts are supported by previous studies of oxime addition to polymers. [24, 25, 36, 37] These new peak environments were also not present in the OCMH and OBZ control spectra (Supplemental Figure 2).

In addition, 13C NMR further supported the observations seen in the 1H NMR. A new peak appeared that was commensurate with an oxime bonding environment ( $\sim 150 \mathrm{ppm})$. Also, changes occurred in the carbonyl carbon environments, especially that of the carboxylic acid at $\sim 174 \mathrm{ppm}$, and ring environments at $\sim 75 \mathrm{ppm}$ corresponding to the grafted side chains (Supplemental Figure 3). Although the data suggested the aminooxy reacted primarily at the carboxylic acid site, the complex spectra for hyaluronan preclude a definitive assignment of the reaction site (Supplemental Figure 4).

Two peptides with aminooxy N-termini were synthesized to further explore this conjugation strategy. During solid phase synthesis, OCMH was simply reacted as the final coupling step to introduce the aminooxy terminus. The peptides synthesized were aminooxy-proteolipid peptide (PLP, aminooxy-HSLGKWLGHPDKF), a multiple sclerosis antigen and aminooxyLABL (LABL, aminooxy-ITDGEATDSG), a cell-adhesion peptide derived from leukocyte function associated-antigen-1 (LFA-1). The peptides were then reacted with HA following the same procedure as with the small molecule probes. Polymers with grafted LABL, or with grafted PLP, were synthesized as well as polymers with both peptide species grafted.

Gel permeation chromatography was used to monitor the increase in apparent molecular weight (MW) of the peptide-HA conjugate products versus the starting HA (Figure 3A). The starting HA and graft polymer products were compared to pullulan standards to calculate final MWs (Figure 3B). An increase in MW was observed that corresponded to the expected products. Grafted PLP showed the greatest shift since PLP (MW=1594) is larger than LABL (MW=1032). The 1:1 ratio of grafted PLP:LABL appeared midway between the other graft products as expected. Additionally, the theoretical number of peptides per HA polymer was calculated using the estimated molecular weights (Table 2).

The graft polymers were furthered analyzed to determine the concentration of peptide that was conjugated to the HA polymer. Oxime bonds are known to be labile to hydrolysis in extremely acidic ( $\leq \mathrm{pH} 2$ ) or extremely basic solutions ( $\geq \mathrm{pH} 9)$. The graft polymer conjugates were incubated in three different $\mathrm{pH}$ solutions and the amount of released peptide was determined using HPLC (Figure 4). At $\mathrm{pH} 2.0$, the peptide was released from HA rapidly and was fully released in $\sim 100 \mathrm{~min}$. At $\mathrm{pH}$ values closer to neutral, peptide was released much slower. 
A mass balance was calculated for the graft polymer conjugates and released peptide based on total reaction times of $8 \mathrm{hrs}$ or $16 \mathrm{hrs}$ (Table 3). A sixteen hour reaction time was sufficient to obtain a conjugation efficiency $>90 \%$.

The final ratio of LABL:PLP peptide on the graft polymer conjugate was calculated based on the amount of released peptide. Peptides were grafted close to the targeted 1:1 ratio (Table 4) suggesting similar reactivity of the two aminooxy-peptides.

An animal study was conducted to investigate how the multivalent presentation of a diseasespecific antigen (PLP) alongside a co-grafted cell-adhesion inhibitor (LABL) would affect disease progression. HA with grafted LABL and PLP peptides ( 1:1 ratio) was injected subcutaneously in the EAE model and significantly suppressed disease when compared to the PBS negative control on days 11-15 ( $\mathrm{p}<0.01)$. The graft polymer conjugates were also compared to a dose of HA equivalent to the concentration of HA dosed with the graft polymer conjugate. Although HA is a known CD-44 antagonist and can induce an antiinflammatory affect, HA did not suppress EAE when compared to PBS while the graft polymer significantly suppressed disease progression (day 11 - 14, p<0.05) (Figure 5A)[38, 39]. The graft polymer conjugates were also compared to a physical mixture of free LABL and PLP peptides to test whether the therapeutic effect was simply due to the presence of both peptide species. The graft polymer conjugate provided significantly lower animal scores when compared to free peptides (days 12-18, p<0.05) (Figure 5B).

The clinical scoring results were further supported by corresponding changes in animal weight during the course of disease and a decrease in the incidence of disease for treated mice (Supplemental Figure 5).

As an additional control, HA grafted with both PLP and LABL was compared in vivo against a physical mixture of the individual scaffold components: HA polymer (MW 16900), LABL peptide, and PLP peptide. The peptides did not contain the aminooxy reactive group. Instead, each peptide had an unreactive amine terminus. The HA grafted with PLP and LABL again significantly suppressed $\mathrm{EAE}(\mathrm{p}<0.05)$ when compared to both the mixture of physical components (Day 12-20) and to PBS (Day 12-21), while the physical mixture showed no statistical difference compared to the PBS injections (Figure 6).

The clinical scoring results were further supported by corresponding changes in animal weight during the course of disease and a decrease in the incidence of disease for treated mice (Supplemental Figure 6).

\section{DISCUSSION}

Oxime chemistry has emerged as a powetful tool in conjugation reactions. Using this scheme, small molecules, Pluronics ${ }^{\circledR}$, and peptides or proteins have been conjugated to polymers [23, 25, 40-42]. Unfortunately, functionalization of both the reactive adduct and the polymer is typically necessary to confer reactivity. These multistep approaches to conjugation can require lengthy and cumbersome synthesis schemes that ultimately produce low yields of the end product. Additionally, when trying to utilize polysaccharide polymers such as hyaluronic acid, functionalization with a reactive aldehyde group can cause the breakdown of the polymer chain leaving a product that is much smaller than desired[43]. Because of these drawbacks, research has relied heavily on other conjugation techniques such as "click chemistry", thiol functionalization, or amine coupling [11, 44]. These approaches also have drawbacks relating to reaction conditions and purification schemes. Techniques such as carboiimde chemistry rely on enhancing the reactivity of carboxylic acids and of primary amines. The potential for side products is high if these groups are present in other parts of the reactive species. Simple conjugation schemes that can provide 
high reactivity and selectivity, with increased product yield via simplified reaction conditions will be desired as more complex polymer conjugates are designed.

Hyaluronic acid has been used in oxime chemistry schemes. Researchers have targeted either the "ring open" aldehyde of the reducing end of hyaluronic acid, or modified aldehyde side groups added to the polymer[29, 43]. Chemical modifications were introduced to encourage the oxime reaction to proceed through the traditional route of aminooxy addition to an aldehyde or ketone. Here, the reactivity of aminooxy molecules directly to unmodified hyaluronic acid was explored. Hyaluronic acid contains two carbonyl functional groups on each monomer unit, a carboxylic acid and a methyl amide, that may confer reactivity. For example, Gajewiak et al. theorized reactivity through the carboxylic acid in the synthesis of their adherent glycosaminoglycan adducts[23].

Initially, a series of experiments were designed to monitor changes in chemical bonds of the polymer and reactive species. Data acquired from FTIR and NMR showed reactivity between small molecules containing the aminooxy group (OCMH and OBZ) and unmodified HA. This was evident from changes in the carboxylic acid and amide environments, as well as the appearance of new bonding environments in the FTIR data and the presence of new peaks in the NMR. The polysaccharide ring environments in both the FTIR and NMR data were maintained, suggesting that the HA backbone remained unchanged. The proton NMR data showed the appearance of three distinct environments, all suggestive of oxime reactivity at the carbonyl carbon centers on the HA molecule. These data run counter to conventional wisdom, which has suggested that any latent reactivity of aminooxy molecules to hyaluronic acid would proceed through "ring opening" of the polymer backbone structure to yield aldehydes[45-47].

After validating the reactivity of small molecule probes, aminoxy peptide species were conjugated to unmodified HA with a high degree of efficiency. Previous research that utilized conjugation techniques such as carboiimide chemistry showed conjugation efficacies of small molecule or peptide species from 10-50\%[48, 49]. Here, data demonstrated that aminooxy chemistry can be used to modify polysaccharides such as HA via a "one pot" reaction with conjugation efficiencies $>90 \%$. The approach reported here could have a dramatic impact on the design of graft polymers, enhancing the ability to synthesize multifunctional conjugates.

The synthesis of multivalent graft polymers is of great interest in the area of immune modulation. Previous research by Dintzis and others have shown that antigen display (i.e. valency, number, density) and polymer characteristics (i.e. molecular weight, solubility) can have dramatic effects on the immune response both in vitro and in vivo[2, 14, 50-52]. In this historical work, immune response was markedly changed by subtle differences in the physicochemical properties of polymers with grafted antigen. More recently, studies investigating priming of T-cells for tumor immunotherapy demonstrated that the colocalization of multiple cell signals could provide an enhanced and directed immune response[53].

Siahaan and others previously demonstrated that the antigenic peptide PLP covalently linked to the cell-adhesion inhibitor LABL suppressed the autoimmune disease EAE [54-57]. By modifying the $N$-terminus of peptides with an aminooxy group, a multivalent graft polymer conjugate displaying both this antigen for multiple sclerosis (PLP) and the cell-adhesion inhibitor LABL was synthesized. HA with both grafted PLP and LABL was tested in vivo in the EAE mouse model, which showed the characteristic peak in clinical scores followed by partial remission of clinical symptoms. The graft polymers significantly suppressed EAE compared to PBS and to HA treatment controls. The graft polymer conjugates also showed 
significant disease suppression compared to a mixture of the free peptides as well as a mixture of all components: HA, PLP, and LABL. All control studies were conducted at similar HA or peptide concentration as the HA with grafted PLP and LABL. Thus, both peptide signals must be coincidently displayed along the polymer backbone to provide therapeutic efficacy, a finding supported by reports from Siahaan and others denoting EAE suppression when directly linking PLP and LABL peptides together $[54,56]$.

\section{CONCLUSION}

A simple approach for grafting aminooxy compounds to HA was proven using chemical and biological studies. Small molecules or peptides containing aminooxy groups were conjugated to hyaluronic acid in a single step under slightly acidic aqueous conditions. Additionally, this oxime chemistry facilitated conjugation of two different peptides (PLP antigen and LABL) to hyaluronic acid in an equimolar ratio. Graft polymers displaying both of these peptides significantly suppressed disease in the EAE mouse model of multiple sclerosis. The "one-pot" reaction scheme presented in this paper offers a simple approach to the synthesis of graft polymers, colloids, or materials that display multiple copies of one or more functional groups. Such an approach may enable new strategies for antigen-specific immune modulation.

\section{Supplementary Material}

Refer to Web version on PubMed Central for supplementary material.

\section{Acknowledgments}

This work was supported by the NIH, KINBRE, Madison and Lila Self Graduate Fellowship, and The Institute for Advancing Medical Innovation Graduate Fellowship. In addition the authors thank Jeff Aube, Tom Prisinzano, Robert Hicklin, Kyle Mendenhall, Kyle Boge, and Carole Schante for their contributions.

\section{ABBREVIATIONS}

$\begin{array}{ll}\text { HA } & \text { hyaluronic acid } \\ \text { OCMH } & \text { O-carboxymethyl hydroxylamine } \\ \text { OPH } & \text { O-phenyl hydroxylamine } \\ \text { OBZ } & \text { O-benxyl hydroxylamine }\end{array}$

\section{REFERENCES}

1. Dintzis HM DR, Vogelstein B. Molecular determinants of immunogenicity: the immunon model of immune response. Proc Natl Acad Sci U S A. 1976; 73:3671-3675. [PubMed: 62364]

2. D. RZ. Rational design of conjugate vaccines. Pediatr Res. 1992; 32:376-385. [PubMed: 1437386]

3. Symer DE RJ, Dintzis RZ, Voss EW Jr, Dintzis HM. Durable elimination of high affinity, T celldependent antibodies by low molecular weight antigen arrays in vivo. J Immunol. 1995; 155:56085616. [PubMed: 7499844]

4. Kiessling LL, Gestwicki JE, Strong LE. Synthetic multivalent ligands as probes of signal transduction. Angew. Chem. Int. Ed. 2006; 45:2348-2368.

5. Puffer EB, Pontrello JK, Hollenbeck JJ, Kink JA, Kiessling LL. Activating B Cell Signaling with Defined Multivalent Ligands. ACS Chemical Biology. 2007; 2:252-262. [PubMed: 17432821]

6. Gilewski T, Adluri S, Ragupathi G, Zhang S, Yao T-J, Panageas K, Moynahan M, Houghton A, Norton L, Livingston PO. Vaccination of High-Risk Breast Cancer Patients with Mucin-1 (MUC1) 
Keyhole Limpet Hemocyanin Conjugate plus QS-21. Clinical Cancer Research. 2000; 6:16931701. [PubMed: 10815887]

7. Helling F, Shang A, Calves M, Zhang S, Ren S, Yu RK, Oettgen HF, Livingston PO. GD3 Vaccines for Melanoma: Superior Immunogenicity of Keyhole Limpet Hemocyanin Conjugate Vaccines. Cancer Research. 1994; 54:197-203. [PubMed: 8261439]

8. Krug LM, Ragupathi G, Ng KK, Hood C, Jennings HJ, Guo Z, Kris MG, Miller V, Pizzo B, Tyson L, Baez V, Livingston PO. Vaccination of Small Cell Lung Cancer Patients with Polysialic Acid or N-Propionylated Polysialic Acid Conjugated to Keyhole Limpet Hemocyanin. Clinical Cancer Research. 2004; 10:916-923. [PubMed: 14871967]

9. Adluri S, Helling F, Ogata S, Zhang S, Itzkowitz SH, Lloyd KO, Livingston PO. Immunogenicity of synthetic TF-KLH (keyhole limpet hemocyanin) and sTn-KLH conjugates in colorectal carcinoma patients. Cancer Immunology, Immunotherapy. 1995; 41:185-192.

10. Shrestha R, Shen Y, Pollack KA, Taylor J-SA, Wooley KL. Dual Peptide Nucleic Acid- and Peptide-Functionalized Shell Cross-Linked Nanoparticles Designed to Target mRNA toward the Diagnosis and Treatment of Acute Lung Injury. Bioconjugate Chemistry. 2012; 23:574-585. [PubMed: 22372643]

11. Marc A. Gauthier, Harm-Anton Klok, ChemInform Abstract: Peptide/Protein - Polymer Conjugates: Synthetic Strategies and Design Concepts. ChemInform. 2008; 39

12. Diezmann F, Eberhard H, Seitz O. Native chemical ligation in the synthesis of internally modified oligonucleotide-peptide conjugates. Peptide Science. 2010; 94:397-404. [PubMed: 20593471]

13. Monteiro, M.B. Gary A.; Femandes, Anthony V.; Sundararaghavan, Harini G.; Shreiber, David I. Positively and Negatively Modulating Cell Adhesion to Type I Collagen Via Peptide Grafting. Tissue Eng Part A. 2011:1663-1673. 12 Ph.D. 1 Ph.D.corresponding author1. [PubMed: 19196133]

14. Dintzis RZ, Okajima M, Middleton MH, Greene G, Dintzis HM. The immunogenicity of soluble haptenated polymers is determined by molecular mass and hapten valence. The Journal of Immunology. 1989; 143:1239-1244. [PubMed: 2473123]

15. Tocce EJ, Broderick AH, Murphy KC, Liliensiek SJ, Murphy CJ, Lynn DM, Nealey PF. Functionalization of reactive polymer multilayers with RGD and an antifouling motif: RGD density provides control over human corneal epithelial cell-substrate interactions. Journal of Biomedical Materials Research Part A. 2012; 100A:84-93. [PubMed: 21972074]

16. Liu JC, Tirrell DA. Cell Response to RGD Density in Cross-Linked Artificial Extracellular Matrix Protein Films. Biomacromolecules. 2008; 9:2984-2988. [PubMed: 18826275]

17. Dintzis RZ MM, Dintzis HM. Inhibition of anti-DNP antibody formation by high doses of DNPpolyacrylamide molecules; effects of hapten density and hapten valence. J Immunol. 1985; 135:423-427. [PubMed: 3889155]

18. Boltje TJ, Buskas T, Boons G-J. Opportunities and challenges in synthetic oligosaccharide and glycoconjugate research. Nat Chem. 2009; 1:611-622. [PubMed: 20161474]

19. Jia X, Colombo G, Padera R, Langer R, Kohane DS. Prolongation of sciatic nerve blockade by in situ cross-linked hyaluronic acid. Biomaterials. 2004; 25:4797-4804. [PubMed: 15120526]

20. Yeo Y, Highley CB, Bellas E, Ito T, Marini R, Langer R, Kahane DS. In situ cross-linkable hyaluronic acid hydrogels prevent post-operative abdominal adhesions in a rabbit model. Biomaterials. 2006; 27:4698-4705. [PubMed: 16750564]

21. Raines, J.K.a.R.T. Advances in Bioconjugation. Curr Org Chem. 2010; 14:138-147. [PubMed: 20622973]

22. Guo Y, Fujiwara K, Uneyama K. A Novel Route to Dipeptides via Noncondensation of Amino Acids: 2-Aminoperfluoropropene as a Synthon for Trifluoroalanine Dipeptides. Organic Letters. 2006; 8:827-829. [PubMed: 16494451]

23. Gajewiak J, Cai S, Shu XZ, Prestwich GD. Aminooxy Pluronics: Synthesis and Preparation of Glycosaminoglycan Adducts. Biomacromolecules. 2006; 7:1781-1789. [PubMed: 16768398]

24. Heredia KL, Tolstyka ZP, Maynard HD. Aminooxy End-Functionalized Polymers Synthesized by ATRP for Chemoselective Conjugation to Proteins. Macromolecules. 2007; 40:4772-4779.

25. Hwang J, Li RC, Maynard HD. Well-defined polymers with activated ester and protected aldehyde side chains for bio-functionalization. J Control Release. 2007; 122:279-286. [PubMed: 17599628] 
26. Jencks WP. Studies on the Mechanism of Oxime and Semicarbazone Formation1. Journal of the American Chemical Society. 1959; 81:475-481.

27. Kalia J, Raines Ronald T. Hydrolytic Stability of Hydrazones and Oximes13. Angewandte Chemie. 2008; 120:7633-7636.

28. Zvilichovsky, G. PATAT'S Chemistry of Functional Groups; Hydroxylamines, Oximes and Hydroxamic acids. In: Online, ZR., editor. Hydroxylamine analogs and derivatives of amino acids. Aminooxy acids. John Wiley \&amp; Sons Ltd; 2010.

29. Novoa-Carballal R, Mueller A. Synthesis of Polysaccharide-b-PEG Block Copolymers by Oxime Click. Chemical Communications. 2012

30. Ossipov DA, Piskounova S, Varghese OP, Hilborn J.n. Functionalization of Hyaluronic Acid with Chemoselective Groups via a Disulfide-Based Protection Strategy for In Situ Formation of Mechanically Stable Hydrogels. Biomacromolecules. 2010; 11:2247-2254. [PubMed: 20704177]

31. Bagby TR, Cai S, Duan S, Thati S, Aires DJ, Forrest L. Impact of Molecular Weight on Lymphatic Drainage of a Biopolymer-Based Imaging Agent. Pharmaceutics. 2012; 4:276-295.

32. Yusuf-Makagiansar H, Makagiansar IT, Hu Y, Siahaan TJ. Synergistic inhibitory activity of [alpha]- and [beta]-LFA-1 peptides on LFA-1/ICAM-1 interaction. Peptides. 2001; 22:1955-1962. [PubMed: 11786177]

33. Chittasupho C, Shannon L, Siahaan TJ, Vines CM, Berkland C. Nanoparticles Targeting Dendritic Cell Surface Molecules Effectively Block T Cell Conjugation and Shift Response. ACS Nano. 2011; 5:1693-1702. [PubMed: 21375342]

34. Chittasupho C, Xie S-X, Baoum A, Yakovleva T, Siahaan TJ, Berkland CJ. ICAM-1 targeting of doxorubicin-loaded PLGA nanoparticles to lung epithelial cells. European Journal of Pharmaceutical Sciences. 2009; 37:141-150. [PubMed: 19429421]

35. Zhang N, Chittsupho C, Duangrat C, Siahaan TJ, Berkland C. PLGA Nanoparticle-Peptide Conjugate Effectively Targets Intercellular Cell-Adhesion Molecule-1. Bioconjugate Chemistry. 2007; 19:145-152. [PubMed: 17997512]

36. Hill MR, Mukherjee S, Costanzo PJ, Sumerlin BS. Modular oxime functionalization of welldefined alkoxyamine-containing polymers. Polymer Chemistry. 2012; 3:1758-1762.

37. Li RC, Broyer RM, Maynard HD. Well-defined polymers with acetal side chains as reactive scaffolds synthesized by atom transfer radical polymerization. Journal of Polymer Science Part A: Polymer Chemistry. 2006; 44:5004-5013.

38. Misra S, Toole BP, Ghatak S. Hyaluronan Constitutively Regulates Activation of Multiple Receptor Tyrosine Kinases in Epithelial and Carcinoma Cells. Journal of Biological Chemistry. 2006; 281:34936-34941. [PubMed: 16959784]

39. Galluzzo E, Albi N, Fiorucci S, Merigiola C, Ruggeri L, Tosti A, Grossi CE, Velardi A. Involvement of CD44 variant isoforms in hyaluronate adhesion by human activated T cells. European Journal of Immunology. 1995; 25:2932-2939. [PubMed: 7589094]

40. Brask J, Jensen KJ. Carbopeptides: chemoselective ligation of peptide aldehydes to an aminooxyfunctionalized D-galactose template. Journal of Peptide Science. 2000; 6:290-299. [PubMed: 10912909]

41. Du, Y.; Mao, D.; Zhang-Negrerie, D.; Zhao, K. PATAI'S Chemistry of Functional Groups. John Wiley \&amp; Sons, Ltd; 2009. Conjugate Addition of Hydorxylamines, Oximes and Hydroxamic Acids.

42. Weikkolainen K, Aitio O, Natunen J, Helin J. Conjugation of oligosaccharides to chondroitin oligomer and $\boldsymbol{\gamma}$-cyclodextrin. Carbohydrate Polymers. 2007; 68:260-269.

43. Ruhela D, Riviere K, Szoka FC. Efficient Synthesis of an Aldehyde Functionalized Hyaluronic Acid and Its Application in the Preparation of Hyaluronan-Lipid Conjugates. Bioconjugate Chemistry. 2006; 17:1360-1363. [PubMed: 16984148]

44. Khandare J, Minko T. Polymer-drug conjugates: Progress in polymeric prodrugs. Progress in Polymer Science. 2006; 31:359-397.

45. Bulpitt P, Aeschlimann D. New strategy for chemical modification of hyaluronic acid: Preparation of functionalized derivatives and their use in the formation of novel biocompatible hydrogels. Journal of Biomedical Materials Research. 1999; 47:152-169. [PubMed: 10449626] 
46. Sun LT, Bencherif SA, Gilbert TW, Farkas AM, Lotze MT, Washburn NR. Biological activities of cytokine-neutralizing hyaluronic acid-antibody conjugates. Wound Repair and Regeneration. 2010; 18:302-310. [PubMed: 20412551]

47. Martínez-Sanz E, Ossipov DA, Hilborn J, Larsson S, Jonsson KB, Varghese OP. Bone reservoir: Injectable hyaluronic acid hydrogel for minimal invasive bone augmentation. Journal of Controlled Release. 2011; 152:232-240. [PubMed: 21315118]

48. Moriyama K, Ooya T, Yui N. Hyaluronic acid grafted with poly(ethylene glycol) as a novel peptide formulation. Journal of Controlled Release. 1999; 59:77-86. [PubMed: 10210724]

49. Luo Y, Prestwich GD. Synthesis and Selective Cytotoxicity of a Hyaluronic Acid-Antitumor Bioconjugate. Bioconjugate Chemistry. 1999; 10:755-763. [PubMed: 10502340]

50. Dintzis HM DR. Antigens as immunoregulators. Immunological Reviews. 1990; 115:243-250. [PubMed: 1697280]

51. Reim JW SD, Watson DC, Dintzis RZ, Dintzis HM. Low molecular weight antigen arrays delete high affinity memory B cells without affecting specific T-cell help. Mol Immunol. 1996; 33:13771388. [PubMed: 9171897]

52. Siliciano RF CR, Keegan AD, Dintzis RZ, Dintzis HM, Shin HS. Antigen valence determines the binding of nominal antigen to cytolytic T cell clones. J Exp Med. 1985; 162:768-773. [PubMed: 2410534]

53. Ochsenbein AF, Sierro S, Odermatt B, Pericin M, Karrer U, Hermans J, Hemmi S, Hengartner H, Zinkernagel RM. Roles of tumour localization, second signals and cross priming in cytotoxic Tcell induction. Nature. 2001; 411:1058-1064. [PubMed: 11429607]

54. Manikwar P, Kiptoo P, Badawi AH, Büyüktimkin B, Siahaan TJ. Antigen-specific blocking of CD4-specific immunological synapse formation using BPI and current therapies for autoimmune diseases. Medicinal Research Reviews. 2011 n/a-n/a.

55. Murray JS, Oney S, Page JE, Kratochvil-Stava A, Hu Y, Makagiansar IT, Brown JC, Kobayashi N, Siahaan TJ. Suppression of Type 1 Diabetes in NOD Mice by Bifunctional Peptide Inhibitor: Modulation of the Immunological Synapse Formation. Chemical Biology \&amp; Drug Design. 2007; 70:227-236. [PubMed: 17718717]

56. Kobayashi, P.K. Naoki; Kobayashi, Hitomi; Ridwan, Rahmawati; Brocke, Stefan; Siahaan, Teruna J. Prophylactic and Therapeutic Suppression of Experimental Autoimmune Encephalomyelitis by a Novel Bifunctional Peptide Inhibitor. Clinical Immunology. 2008; 129:69-79. [PubMed: 18676182]

57. Satyanarayanajois SD, Büyüktimkin B, Gokhale A, Ronald S, Siahaan TJ, Latendresse JR. A Peptide from the Beta-strand Region of CD2 Protein that Inhibits Cell Adhesion and Suppresses Arthritis in a Mouse Model. Chemical Biology \&amp; Drug Design. 2010; 76:234-244. [PubMed: 20572813] 


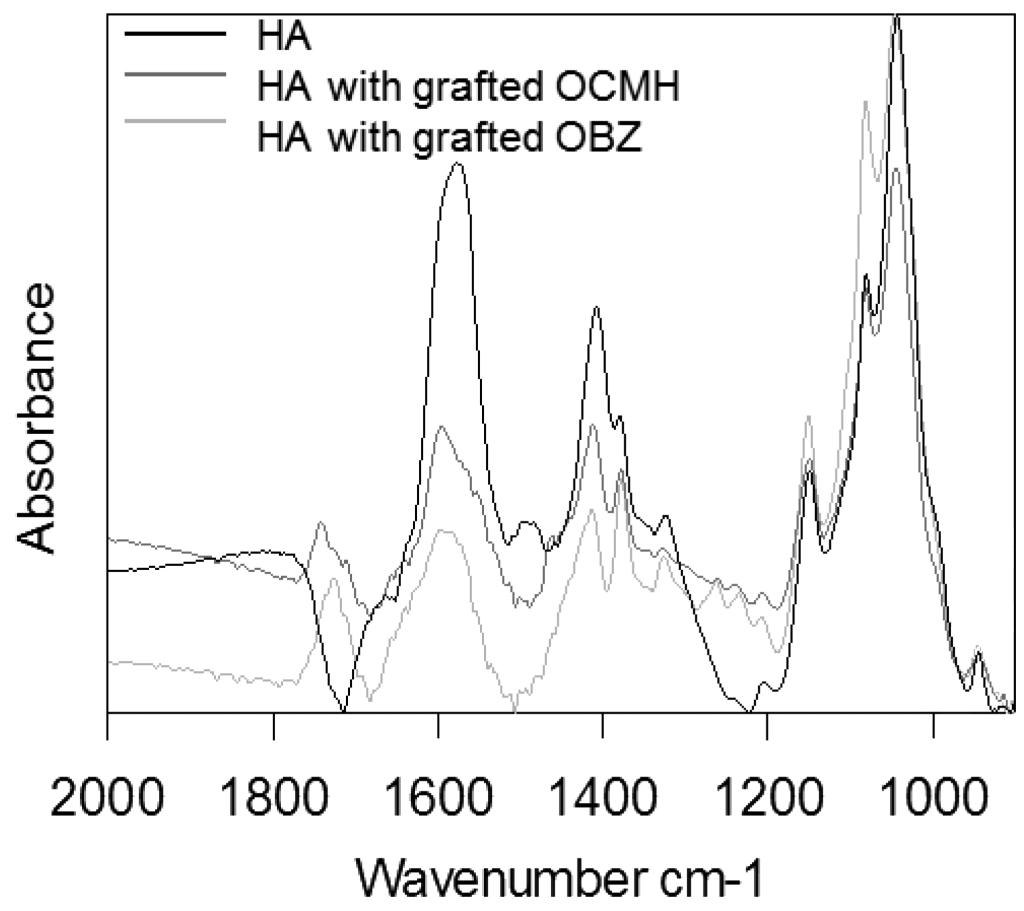

Figure 1.

The FTIR spectra of graft polymer products showed new peaks at $\sim 1750$ and $\sim 1250 \mathrm{~cm}-1$ and loss of the peak at $\sim 1500 \mathrm{~cm}-1$ when compared to the HA spectra (Supplemental Figure $1)$. 


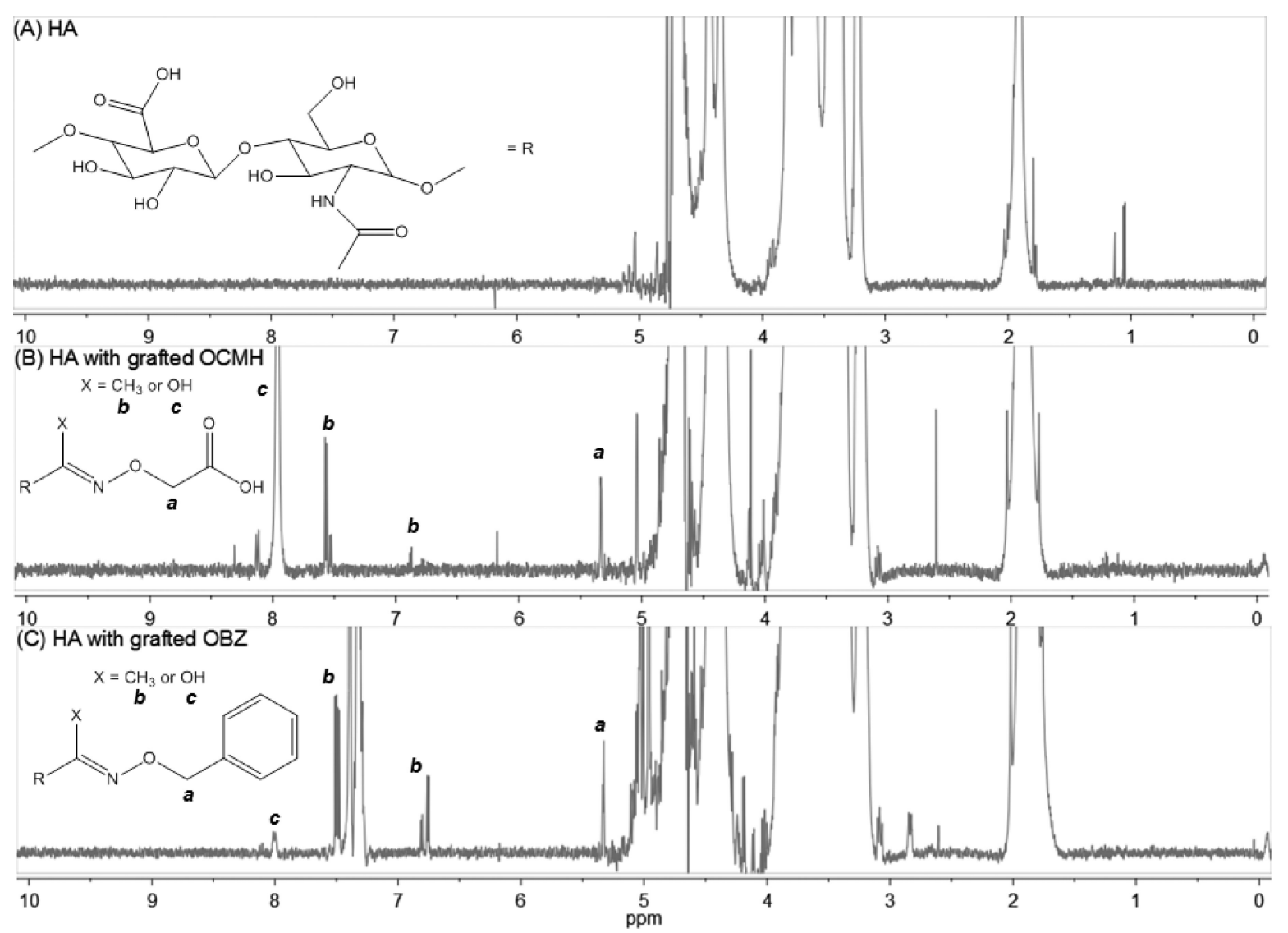

Figure 2.

1H NMR spectra for (A) HA, and for graft polymer products with (B) OCMH or (C) OBZ. The OCMH and OBZ spectra show the appearance of new peaks suggesting oxime bond formation at $a-5.3 \mathrm{ppm}, b-\sim 6.9$ and $7.5 \mathrm{ppm}$, and $c-8 \mathrm{ppm}$. All data was compared to HA and the individual monomer controls (Supplemental Figure 2). 
(A)

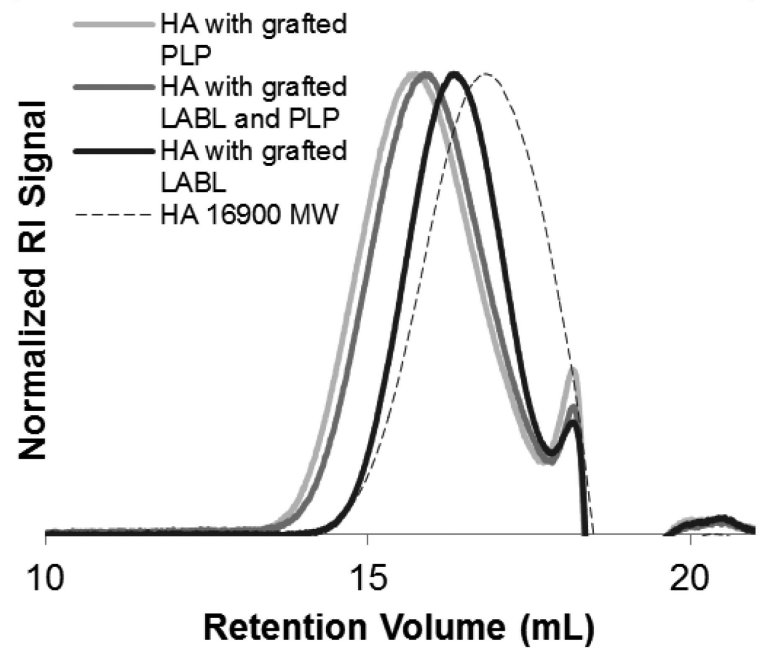

(B)

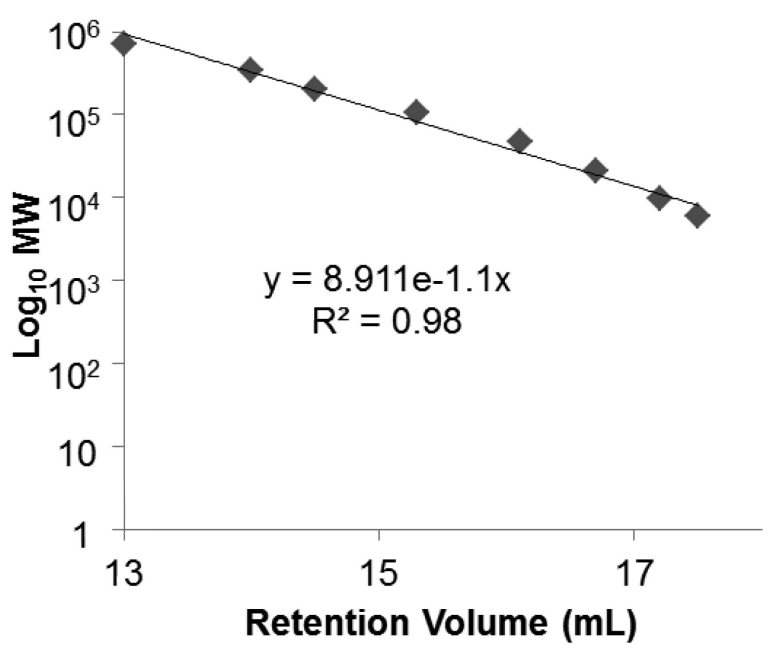

Figure 3.

(A) SEC analysis of HA grafted with a single peptide (PLP or LABL) or grafted with a 1:1 peptide mixture showed an increase in MW as compared to unmodified HA. (B) Calibration curve for pullulan standards used to calculate HA polymer graft conjugate product MW. 


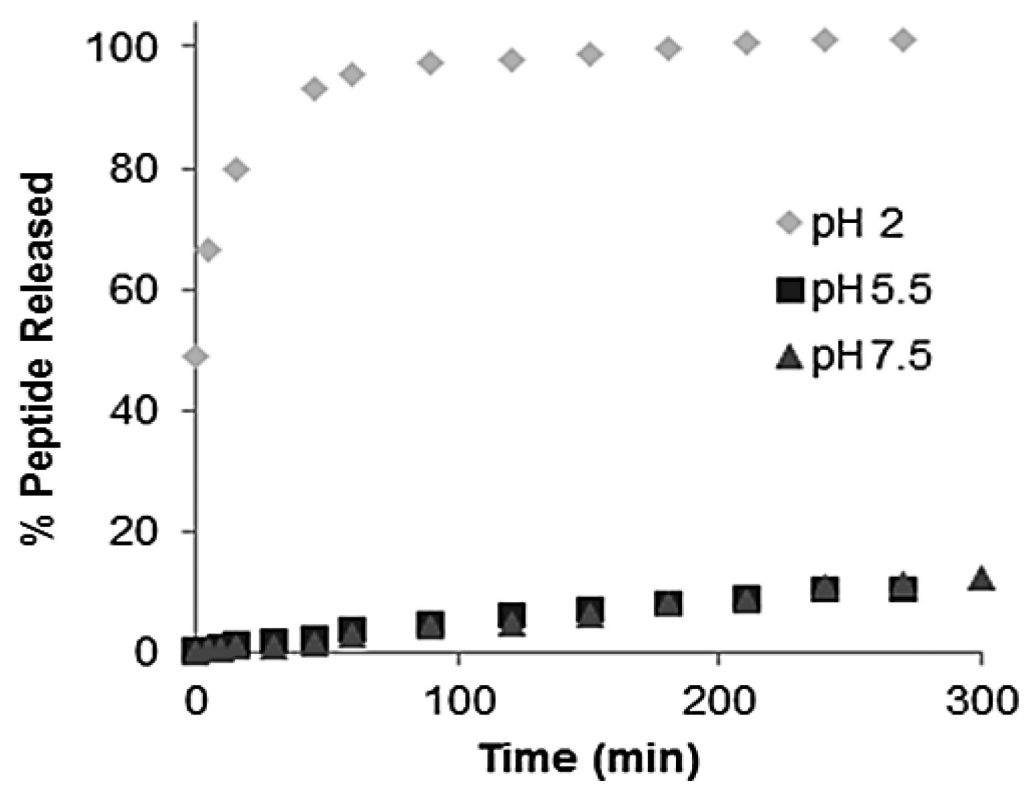

Figure 4.

The release of LABL peptide from HA was determined in three buffer conditions. Peptide was released rapidly at $\mathrm{pH} 2$. 
(A)

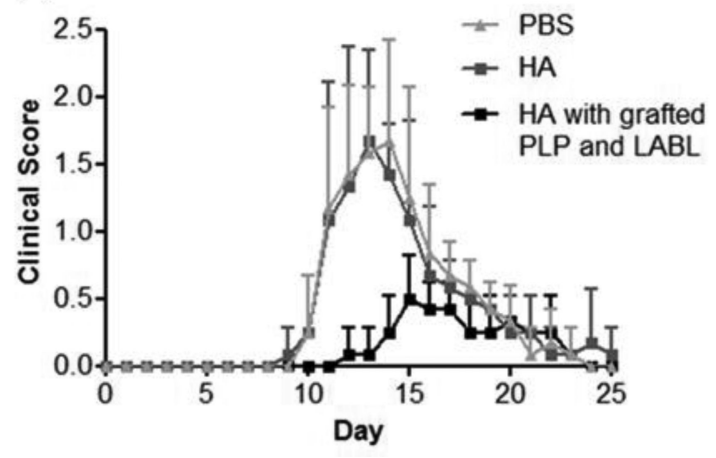

(B)

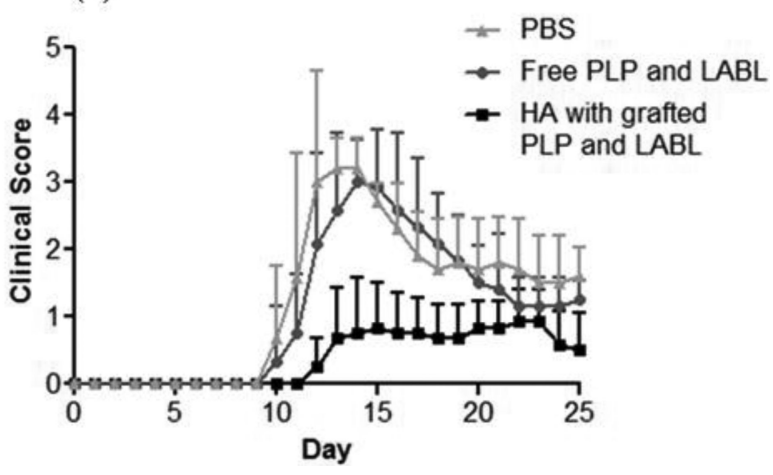

Figure 5.

Graft polymer conjugates were evaluated in the EAE model. (A) HA grafted with PLP and LABL significantly suppressed disease $(\mathrm{p}<0.05)$ when compared to both HA polymer (Day 11-14) alone and PBS controls (Day 11-15). (B) A physical mixture of free PLP and LABL peptides showed no effect when compared to PBS control. Conversely, HA grafted with PLP and LABL did significantly suppress disease (Day 12-18). 


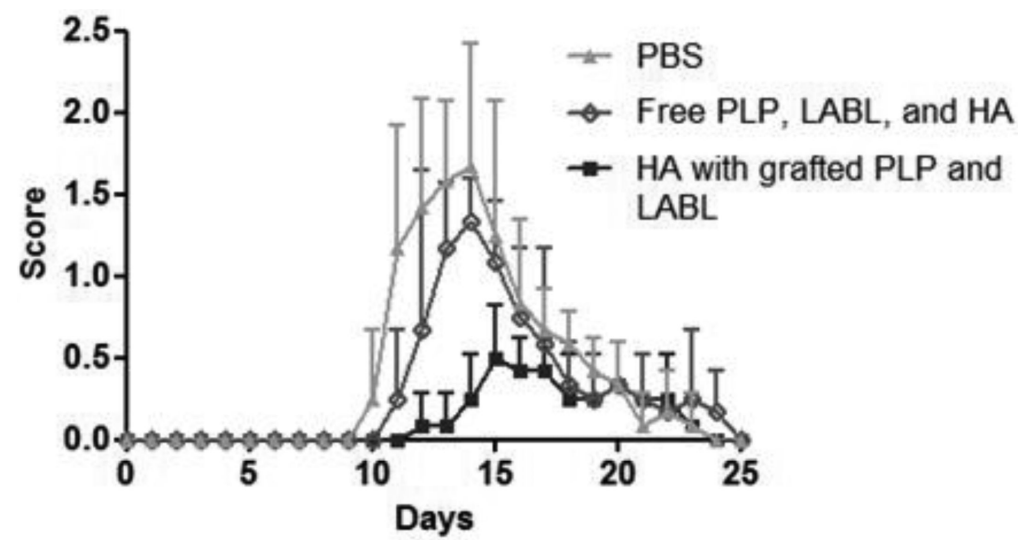

Figure 6.

HA grafted with PLP and LABL was compared to a physical mixture of HA, PLP peptide, and LABL peptide. HA grafted with PLP and LABL significantly suppressed disease $(\mathrm{p}<0.05)$ when compared to both the physical mixture (Days 12-20) and to PBS controls (Days 12-21). The physical mixture of all components showed no effect when compared to PBS control. 
Table 1

Structures of hyaluronic acid and aminooxy probes used for testing reactivity.

\begin{tabular}{|l|l|}
\hline Molecule & Structure \\
\hline Hyaluronic Acid Monomer & O-carboxymethyl hydroxylamine \\
\hline O-phenyl hydroxylamine & \\
\hline O-benzyl hydroxylamine & \\
\hline
\end{tabular}


Table 2

Calculated MWs for graft polymer conjugate products based on SEC.

\begin{tabular}{|l|c|c|}
\hline Sample & Calculated MW & Theoretical Peptides per HA polymer \\
\hline HA with grafted LABL & 32145 & 31 \\
\hline HA with grafted PLP & 60646 & 38 \\
\hline HA with grafted LABL and PLP & 49080 & 37 \\
\hline
\end{tabular}

Molecular weight estimated from pullulan standards 
Table 3

Mass balance of grafted HA (31 kDa) and unreacted aminooxy-LABL for the reaction times indicated.

\begin{tabular}{|c|c|c|c|c|}
\hline Sample & Area Under Curve & Total Area of Peaks & Reaction Efficiency & Theoretical LABL per HA polymer \\
\hline Aminooxy-LABL Peptide & 8799141 & 8799141 & $\mathrm{n} / \mathrm{a}$ & $\mathrm{n} / \mathrm{a}$ \\
\hline Grafted peptide $(8 \mathrm{hr}){ }^{*}$ & 5633361 & \multirow{2}{*}{8774823} & \multirow{2}{*}{$\sim 64 \%$} & \multirow{2}{*}{26} \\
\hline Unreacted peptide $(8 \mathrm{hr})^{* *}$ & 3141462 & & & \\
\hline Grafted peptide $(16 \mathrm{hr})^{*}$ & 8421520 & \multirow{2}{*}{8421520} & \multirow{2}{*}{$\sim 96 \%$} & \multirow{2}{*}{41} \\
\hline Unreacted peptide $(16 \mathrm{hr})^{* *}$ & Not detected & & & \\
\hline
\end{tabular}

* Peptide was first hydrolyzed from $\mathrm{HA}$ at $\mathrm{pH} 2$

***

Total unreacted peptide in dialysate washes 
Table 4

HPLC analysis of peptides released from the HA $(31 \mathrm{kDa})$ graft polymer.

\begin{tabular}{|l|c|c|c|}
\hline Peptide & Concentration (nMol) & Mol\% & Theoretical \# Peptide per HA polymer \\
\hline Aminooxy-LABL Peptide & 650 & 54 & 22 \\
\hline Aminooxy-PLP Peptide & 550 & 46 & 19 \\
\hline
\end{tabular}

